Proceedings of the XXIII Conference on Applied Crystallography, Krynica Zdrój, Poland, September 20-24, 2015

\title{
Structure and Corrosion Resistance of Nickel-Molybdenum Alloy Coatings
}

\author{
M. PopczyK*, M. Zacharz, P. Osak, G. Dercz and B. Łosiewicz \\ Institute of Materials Science, University of Silesia, 75 Pułku Piechoty 1A, 41-500 Chorzów, Poland
}

\begin{abstract}
Electrolytic Ni-Mo alloy coatings were obtained from the galvanic bath, at the temperature of $T=60^{\circ} \mathrm{C}$ under galvanostatic conditions using a cathodic current density of $j=80 \mathrm{~mA} \mathrm{~cm}^{-2}$. Surface morphology was studied using a scanning electron microscopy. Chemical composition of obtained coatings was determined by the energy dispersive spectroscopy. Structural studies were carried out using an X-ray diffraction method. Electrochemical corrosion resistance tests were carried out in $5 \% \mathrm{NaCl}$ solution. It was found that $\mathrm{X}$-ray diffraction investigations of all obtained coatings showed the characteristic "halo", which suggests that the obtained deposits have an amorphous structure. Chemical composition and corrosion resistance of the electrolytic Ni-Mo coatings depend on the concentration of $\mathrm{Na}_{2} \mathrm{MoO}_{4} \cdot 2 \mathrm{H}_{2} \mathrm{O}$ in a galvanic bath. With the increase of the molybdenum content in the alloy coatings, their corrosion resistance increases.
\end{abstract}

DOI: $10.12693 /$ APhysPolA.130.1072

PACS/topics: 81.15.-z, 82.45.Qr, 82.45.Bb

\section{Introduction}

The electrochemical properties of nickel-based alloy are well known. Their wide application is a result of specific properties of nickel, which exhibits good corrosion resistance in aggressive solutions and a high catalytic activity for many electrochemical processes. In order to enhance the utilization of nickel electrocoatings, various modifications can be applied, such as the use of alloys instead of the pure element [1-5]. Recently, it was reported that Ni-Mo alloy coatings of a high Mo content can be obtained from pyrophosphate galvanic baths [3-5]. The study examined the influence of the content of sodium molybdate in a galvanic pyrophosphate bath on the surface morphology, chemical and phase composition, and corrosion resistance of the obtained coatings.

\section{Experimental}

$\mathrm{Ni}$-Mo alloy coatings were obtained by electrodeposition from the following bath (concentrations in $\mathrm{g} \mathrm{dm}^{-3}$ ): $\mathrm{K}_{4} \mathrm{P}_{2} \mathrm{O}_{7}-45, \mathrm{NiCl}_{2} \cdot 6 \mathrm{H}_{2} \mathrm{O}-10, \mathrm{Na}_{2} \mathrm{MoO}_{4} \cdot 2 \mathrm{H}_{2} \mathrm{O}$ $-x(x=5,15,25,35,45,55,65)$ and $\mathrm{NaHCO}_{3}$ - 75, under galvanostatic conditions using a cathodic current density of $j=80 \mathrm{~mA} \mathrm{~cm}{ }^{-2}$. Distilled water and "analytical grade" reagents were used for preparation of the bath. The process was carried out at the temperature of $60^{\circ} \mathrm{C}$. A sheet nickel served as an auxiliary electrode. The coatings were deposited on the steel substrate (S235) of the geometric surface area of $1 \mathrm{~cm}^{2}$. The surface morphology of the coatings was studied using a scanning electron microscope (JEOL JSM6480). Chemical analysis of the coatings was determined by energy dispersive spectroscopy. Phase composition investigations were conducted by X-ray diffraction

\footnotetext{
* corresponding author; e-mail: magdalena.popczyk@us.edu.pl
}

method using Philips X'Pert PW 3040/60 X-ray diffractometer $(U=40 \mathrm{kV}, I=30 \mathrm{~mA})$ with copper radiation $\left(\lambda\left(\mathrm{Cu} K_{\alpha}\right)=1.54178 \AA\right)$. Electrochemical corrosion resistance investigations on the prepared coatings were conducted in a three-electrode cell, using open circuit potential method and potentiodynamic measurements. These measurements were carried out in $5 \% \mathrm{NaCl}$ solution, at the temperature of $20^{\circ} \mathrm{C}$, using Autolab PGSTAT30 Potentiostat/Galvanostat Electrochemical System. The auxiliary electrode was a platinum mesh and the reference electrode was the saturated calomel electrode (SCE). Values of corrosion potential, corrosion current, and polarization resistance were determined by the Stern method.

\section{Results and discussion}

Independently of the bath type, the obtained $\mathrm{Ni}-\mathrm{Mo}$ alloy coatings had a metallic, dark grey surface (Fig. 1). Chemical composition of coatings depends on the content of sodium molybdate in a galvanic bath. With the increase in the content of this component in a galvanic bath there increases the molybdenum content in the coating. The maximal content of Mo was found to be 63.5 at.\% (Table I).

Independently of the content of sodium molybdate in a galvanic bath, for all obtained Ni-Mo coatings in XRD patterns the characteristic "halo" was observed which suggests that the obtained deposits have an amorphous structure (Fig. 2).

Electrochemical corrosion resistance tests were carried out in $5 \% \mathrm{NaCl}$ solution. Potential of open circuit of coatings was determined after $20 \mathrm{~h}$. Based on the obtained value of the open circuit potential a range $\pm 0.050 \mathrm{~V}$ was chosen for further potentiodynamic measurements with

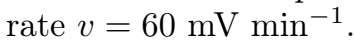

On the basis of the obtained dependences $j=f(E)$ values of corrosion parameters were determined. It was 

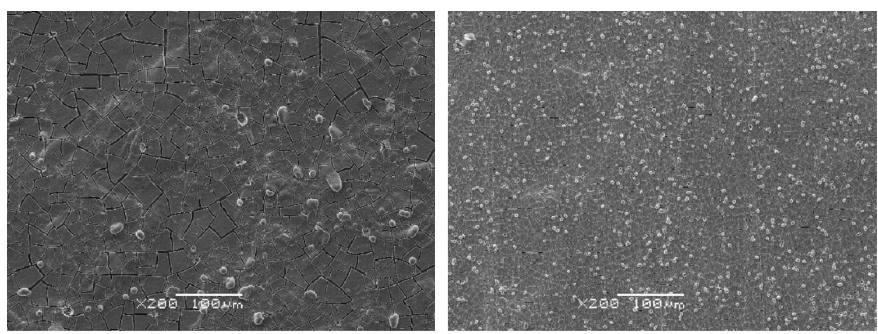

a)

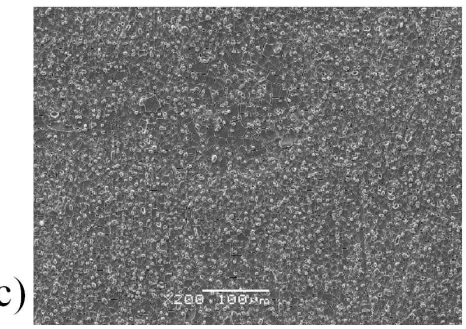

b)

c)
Fig. 1. Surface morphology of the Ni-Mo alloy coatings in dependence on the content of sodium molybdate in a galvanic bath (a) 15 , (b) 35 and (c) $65 \mathrm{~g} \mathrm{dm}^{-3}$.

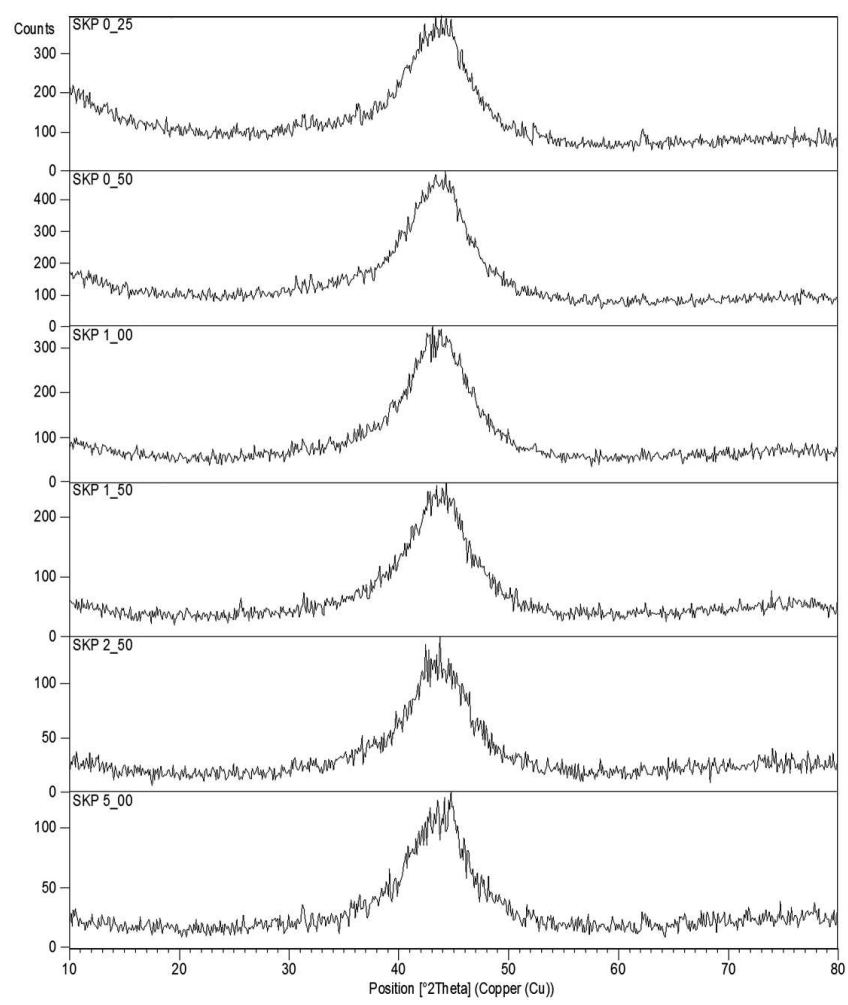

Fig. 2. The XRD pattern of the Ni-Mo alloy coating (63.5 at.\% of Mo).

found that for the Ni-Mo alloy coating (63.5 at.\% of Mo), value of corrosion current, $j_{\text {corr }}$, is least and value of corrosion potential, $E_{\text {corr }}$, is more positive in comparison with others coatings (Fig. 3, Table II). This coating is also characterized by the highest value of polarization resistance, $R_{p}$. Based on these studies it was found that with the increase in the molybdenum content in the alloy coatings, their corrosion resistance increases.
TABLE I

Chemical composition [at.\%] of the Ni-Mo alloy coatings in dependence on the contents $x\left[\mathrm{~g} \mathrm{dm}^{-3}\right]$ of $\mathrm{Na}_{2} \mathrm{MoO}_{4}$. $2 \mathrm{H}_{2} \mathrm{O}$ in a galvanic bath.

\begin{tabular}{c|c|c}
\hline \hline$x$ & $\mathrm{Ni}$ & Mo \\
\hline 5 & 44.5 & 55.5 \\
15 & 43.6 & 56.4 \\
25 & 43.2 & 56.8 \\
35 & 43.1 & 56.9 \\
45 & 42.3 & 57.7 \\
55 & 40.7 & 59.3 \\
65 & 36.5 & 63.5
\end{tabular}

TABLE II

Corrosion parameters of the $\mathrm{Ni}-\mathrm{Mo}$ alloy coatings in dependence on the contents $x\left[\mathrm{~g} \mathrm{dm}^{-3}\right]$ of $\mathrm{Na}_{2} \mathrm{MoO}_{4} \cdot 2 \mathrm{H}_{2} \mathrm{O}$ in a galvanic bath.

\begin{tabular}{c|c|c|c}
\hline \hline$x$ & $E_{\text {corr }}[\mathrm{V}]$ & $j_{\text {corr }}\left[\mu \mathrm{m} \mathrm{cm}^{-2}\right]$ & $R_{p}\left[\Omega \mathrm{cm}^{2}\right]$ \\
\hline 5 & -0.687 & 19.3 & 516 \\
15 & -0.654 & 17.1 & 600 \\
25 & -0.643 & 11.6 & 663 \\
35 & -0.626 & 7.6 & 728 \\
45 & -0.618 & 6.0 & 807 \\
55 & -0.616 & 4.6 & 1256 \\
65 & -0.601 & 2.9 & 1911
\end{tabular}

It should be added that the all $\mathrm{Ni}-\mathrm{Mo}$ alloy coatings show higher corrosion resistance as compared to steel substrate value of the $E_{\text {corr S235 }}=-0.739 \mathrm{~V}$ and is shifted towards negative values compared with $\mathrm{Ni}-\mathrm{Mo}$ alloy coatings (Fig. 3).

\section{Conclusions}

Based on the tests of the Ni-Mo alloy coatings it was found that with the increase in the molybdenum content

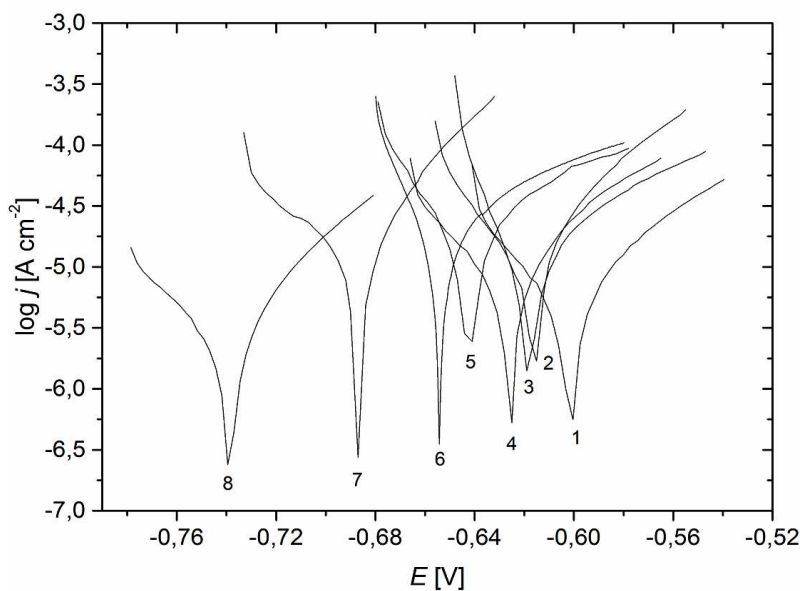

Fig. 3. $\log j=f(E)$ for the Ni-Mo alloy coatings in dependence on the content $x\left[\mathrm{~g} \mathrm{dm}^{-3}\right]$ of $\mathrm{Na}_{2} \mathrm{MoO}_{4}$. $2 \mathrm{H}_{2} \mathrm{O}$ in a galvanic bath: $1-65,2-55,3-45$, $4-35,5-25,6-15,7-5$, and for the substrate: 8 - S235 steel. 
in the alloy coatings, their corrosion resistance increases. The value of polarization resistance increases, the value of the corrosion current decreases, and value of the corrosion potential is shifted towards positive values. This suggests a positive effect of increase content of Mo in the Ni-Mo coatings on their corrosion resistance. These coatings may be regarded as a protective coating for steel substrate.

\section{References}

[1] J. Lelatko, T. Goryczka, T. Wierzchon, M. Ossowski, B. Losiewicz, E. Rowinski, H. Morawiec, Solid State Phenom. 163, 127 (2010).
[2] M. Freitag, B. Losiewicz, T. Goryczka, J. Lelatko, Solid State Phenom. 183, 57 (2012).

[3] B. Łosiewicz, G. Dercz, M. Popczyk, Solid State Phenom. 228, 116 (2015).

[4] B. Łosiewicz, M. Popczyk, Solid State Phenom. 228, 269 (2015).

[5] N.V. Krstajić, V.D. Jović, Lj. Gajić-Krstajić, B.M. Jović, A.L. Antozzi, G.N. Martelli, Int. J. Hydrogen En. 33, 3676 (2008). 